\title{
Circular Economy Business Model and Purchase Intention for Recycled PET Products by Brazilian Consumers
}

\author{
Fernanda Cristina Barbosa Pereira Queiroz ${ }^{1}$, Nilton Cesar Lima ${ }^{2, *}$, Christian Luiz da Silva ${ }^{3}$, Jamerson Viegas \\ Queiroz ${ }^{4}$ and Gustavo Henrique Silva de Souza ${ }^{5}$ \\ 1 Universidade Federal do Rio Grande do Norte; fernandacbpereira@gmail.com \\ 2 Universidade Federal de Uberlândia; cesarlim@yahoo.com \\ * Correspondence: cesarlim@yahoo.com; Tel.: (+55 3499340 9055) \\ 3 Universidade Tecnológica Federal do Paraná; christianlsilva76@gmail.com \\ 4 Universidade Federal do Rio Grande do Norte; viegasqueiroz@gmail.com \\ 5 Instituto Federal do Norte de Minas Gerais; souza.g.h.s@gmail.com
}

\begin{abstract}
Circular Economy involves structural changes in traditional business models and consumers' behaviour toward recycled products. The recycling of PET products has been increasing but there is still a gap between consumption and demand for PET packaging in Brazil. In this research, the waste reduction was examined under a projective scenario to the current ecological purposes in Brazil for reducing environmental pollution. In that manner, this paper aimed to comprehend the intention to purchase recycled PET products of Brazilian consumers. With a non-probabilistic and convenience sample, the study counts 422 participants. The method employed was based on Structural Equation Modelling and Partial Least Squares, used to test the hypotheses of causality among the variables. Results showed the perception of low quality about recycled products reduced consumers' intention to purchase. Also, the sustainability of recycled products positively influenced the intention to purchase. In addition, recycled products presented a negative impact on the perceived safety, which could influence the purchase of recycled products in Brazil. We conclude that the image that Brazilian consumers have about recycled products positively affects the intention to purchase.
\end{abstract}

Keywords: recycled PET products; circular economy; intention to purchase.

\section{Introduction}

Although the discussions on Circular Economy (CE) are not current, the subject is becoming increasingly popular and presenting a growing number of studies and publications in recent years. If, on the one hand, $\mathrm{CE}$ has become the subject of effective public policies, demanding investments for changes in production systems and consumption patterns [1]; on the other hand, only $8.6 \%$ of minerals, fossil fuels, metal, and biomass that enter the economy were recycled in 2020 - in 2018 this percentage was $9.1 \%$ [2].

Rapid population growth and urbanization have considerably increased consumption. However, from another perspective, natural resources remain finite and scarce, reinforcing the need to rethink the current linear economic model and the practice of extractproduce-discard $[3,4,5]$.

$\mathrm{CE}$ comprises an economic system that aims at zero waste and pollution throughout the entire life cycle of materials, from extraction (withdrawing materials from the environment) to industrial transformation [6]. Therefore, CE represents a new model of economic development through promoting maximum reuse/recycling of materials to reduce as much as possible the generation of waste. The techniques used aim to maintain products, components, materials, and energy in circulation to continue increasing and maintaining their value for a long time, which involves changes in traditional business models 
[7]. This is a model for implementing sustainability by reducing the consumption of energy, materials, and resources, having as principles the 3Rs - Reduce, Reuse and Recycle - used in the production, circulation, and consumption processes [8].

The concept and practice of CE are not hegemonic or devoid of criticism, and there are some theoretical discussions on the controversial relationships of topics associated with $\mathrm{CE}$, for example: economic growth, costs and economic viability, biodiversity, materials and energy, product design, logistics operations, business models, and data management. Another criticism refers to the lack of incorporation of the social issue in discussions on CE. The lack of empirical studies on the topic and its implications is also evident, especially in developing countries, whose economies are most intensive in the extraction of natural resources $[1,9,10,11]$.

Given the background, this research sought to validate [4] model concerning consumer acceptance for recycled products in the Brazilian context. In the authors' opinion, the key factor to ensuring the success of circular business models is to understand the determinants of consumers' acceptance for recycled products.

The model was initially employed in Spain, and the results indicated that the positive image and safety of recycled products comprised the essential factors for consumers' acceptance. This model was adapted and applied in Vietnam to identify the contribution of variables to determine the purchase intention of clothing products from waste polyethylene terephthalate (PET) bottles [12]. The authors determined three factors significantly affecting product acceptance: quality, sustainability, and safety.

In Brazil, the recycling of PET products has been increasing, but there is still a gap between consumption and demand for PET packaging. At this point, we formulate the question guiding this research: What are the determinants of Brazilian consumers' acceptance for recycled PET products?

This paper aims to understand the purchase intention for recycled PET products by Brazilian consumers. The study is based on green consumption and waste reduction, considering the model from $[4,12]$. This aim partakes of a projective scenario to the current ecological objectives in Brazil to reduce environmental pollution.

This study equally suits an applied approach since the stakeholders involved in postconsumer recycling will be investigated regarding their perceptions and motivations. It will help to recognize the factors that may contribute to the growth of CE in this segment. In other words, in an emerging economy like Brazil, this study's findings might help establish the $\mathrm{CE}$ and understand the chain and the reasons that drive post-consumer PET bottle recycling.

This paper is divided into five sections, including this introduction. In the following section, we define the $\mathrm{CE}$ and ground the relationship between this theme and recycling. The methodology, reported in the third section, depicts the procedures to support the research findings. In the fourth section, we present the results within a theoretical base besides the hypothesis validation. In closing, we bring the conclusions and proposals for further discussions.

\section{Circular Economy (CE)}

Discussions about CE maintain a current emphasis notwithstanding not have an established conceptual structure and notoriety in the scientific field. The investigative locus associated with CE has been essentially vast and transversal, linking economic development to numerous aspects, for example: the more efficient use of natural resources; the encouragement of new business models, in which manufacturing processes can be optimized under dependence on alternative raw materials; and, the preference for more durable, recyclable, and renewable inputs.

CE emerged in the 1970s from the idea of reducing the consumption of inputs for industrial production and currently shows to be potentially applicable to any resource [13]. 
Regardless of the scientific characterization of CE, it has already been configured in micro, meso, and macro-level environments, involving governments, global organizations (like the UN), the entire private sector, researchers, consumers, and individuals [6]. Researchers have awakened to the $\mathrm{CE}$, as we can observe from the evolution of publications (see Figure 1).

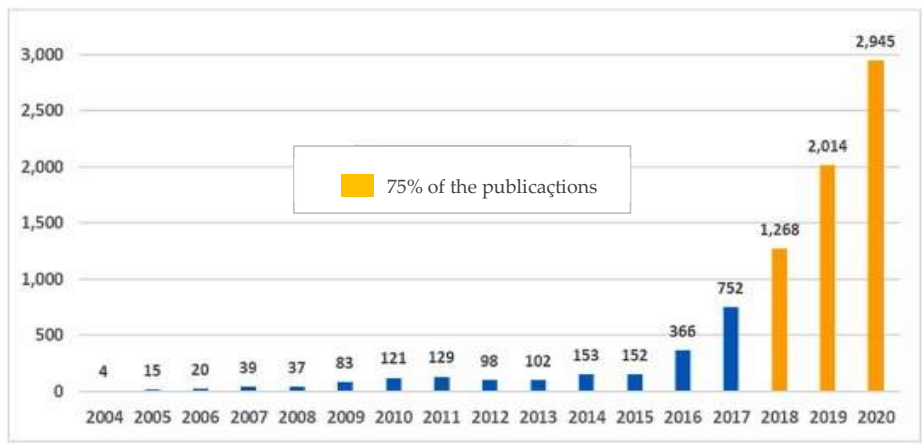

Figure 1. Publications on CE published in Scopus ${ }^{\circledR}$ database. Source: [6].

According to [6], the growth of research in CE is due to activist efforts undertaken by the Ellen MacArthur Foundation (EMF) since its foundation in 2010, and its global partners, which includes large organizations such as Google, Unilever, Philips, and Renault. The researchers still bring the CE as a subject under construction and that contemplates numerous conceptual definitions. As shown in Table 1, authors who work with concepts of CE are categorized according to citations in the Scopus ${ }^{\circledR}$ database.

Table 1. Main precursors in the definition of CE, cited in the Scopus ${ }^{\circledR}$ base.

\begin{tabular}{|c|c|c|}
\hline Author/Year & Citation $^{1}$ & Definition of CE \\
\hline $\begin{array}{l}\text { Ghisellini, Patrizia - } \\
2018 .\end{array}$ & 1,495 & $\begin{array}{l}\text { EC represents a new model of economic development by promoting max- } \\
\text { imum reuse/recycling of materials to reduce waste generation as much as } \\
\text { possible. It aims to innovate the entire chain of production, consumption, } \\
\text { distribution, and recovery of materials and energy. }\end{array}$ \\
\hline $\begin{array}{l}\text { Geissdoerfer, Martin } \\
-2017 \text {. }\end{array}$ & 1,364 & $\begin{array}{l}\text { EC corresponds to a regenerative system in which resource input, resource } \\
\text { waste, emissions, and energy leakage are minimized by slowing down, } \\
\text { closing, and tightening material and energy circuits. This process can be } \\
\text { achieved through design, maintenance, repair, re-use, remanufacturing, } \\
\text { refurbishment, and long-term recycling. }\end{array}$ \\
\hline $\begin{array}{l}\text { Kirchherr, Julian - } \\
2019 .\end{array}$ & 1,205 & $\begin{array}{l}\text { CE constitutes an economic system directed towards the reuse, recycling, } \\
\text { and recovery of materials in the production process, including distribution } \\
\text { and consumption. CE is in micro-level (products, companies, and consum- } \\
\text { ers), meso-level (eco-industrial parks), and macro-level (city, region, and } \\
\text { nation) to achieve sustainable development; therefore, promoting simulta- } \\
\text { neously environmental quality, economic prosperity, and social equity, for } \\
\text { the benefit of current and future generations. It stimulates new business } \\
\text { models and responsible consumers. }\end{array}$ \\
\hline $\begin{array}{l}\text { Bocken, Nancy MP - } \\
2016 .\end{array}$ & 1,137 & $\begin{array}{l}\text { CE is about a circular approach that contrasts with the traditional linear } \\
\text { business model (e.g., dependent on fossil fuels). For that, CE aims not only }\end{array}$ \\
\hline
\end{tabular}


Korhonen, Jouni -

2017.

867

Ellen MacArthur

Foundation $^{2}-2013$. to generate profits from the sale of its products but to generate profits from the flow of materials throughout production that allows them to be reused.

$\mathrm{CE}$ is an economic model based on social systems of production and consumption that maximize productivity from the flow of renewable energy sources and recyclable material. A successful CE contributes to all dimensions of sustainable development. CE limits the production flow to a level that nature tolerates, respecting ecosystem cycles and the natural reproduction rates.

$\mathrm{CE}$ is based on the principles of eliminating waste and pollution, maintaining products and materials in use, and regenerating natural systems.

Source: Adapted from [6]. Notes: ${ }^{1}$ The most considerable number of citations until April 2021. ${ }^{2}$ Citation not referenced in Scopus ${ }^{\circledR}$ base, being a Charitable Foundation registered in the UK of expressive conceptual contribution mentioned in Scopus ${ }^{\circledR}$ base.

Table 1 consolidates the classical definitions of CE. However, there are other definitions with many citations (over 1,000 citations in 2020) found in the Scopus ${ }^{\circledR}$ database. These citations [14], consists of a list of principles for CE: design, reduce, reuse, recycle, reclassification of technical materials and nutrients, and renewable energy. These principles have served as the basis for several recent studies in CE.

Other seminal researchers for defining CE are Dr. Julian Kirchherr, Denise Reike, and Marko Hekkerta. They published the paper "Conceptualizing the circular economy: an analysis of 114 definitions", in which proposed the following definition for CE: Reduce, Reuse, Recycle, Recover (4Rs); Waste Hierarchy; Systems Perspective (Micro-MesoMacro); and the Triple Bottom Line (business models, consumers, and sustainability) [15].

Nevertheless, there is no consensus on CE definitions and terminology due to the confusion with other concepts in the sustainability area - such as green economy, clean production, or industrial ecology [16]. Even so, under the existence of several concepts associated, the repercussions for society and the constitution of environmental public policies sound positive when considering its terminological essence.

If an organization can reuse or recycle its waste, it can somehow be considered inserted in the CE [6]. However, they warn some cases do not configure CE, e.g.: a transport company that performs the oil change routine and properly cares for the oil removed from trucks but does not filter pollutant emissions and continues to consume fossil fuels. In this example, some principles are applied, but it nonetheless cannot be considered CE.

In this sense, propose an alternative definition for CE [6] (p. 10): “Circular Economy comprises an economic system that targets zero waste and pollution throughout the entire life cycle of materials, from extraction in the environment to the industrial transformation". In addition, CE is based on: the conception of manufactured products with added value and maximum use in longer life cycles; the creation of versatile products with various usages that provide greater reuse; the restitution of solid waste in a controlled manner, whereby the cost of secondary raw materials from recycling is competitive in the marketplace; as well as a systemic approach to supply chain management, assessing the interconnections between the energy, the extracted material, and the environment [16].

In this way, we highlight three aspects: (i) there are deficiencies in the CE concept; (ii) not all CE concepts come from the scientific community; and (iii) the theme has been worked exclusively in the academic sphere. Therefore, it is possible to identify that the terminological essence for CE is established merely in the strategies for extending the useful life of resources.

The CE remains an essential condition for sustainability, being as principal actors in this transition process the private companies [16].

\section{Recycling of PET products in Brazil}


PET products stand out as the most widely used packaging material worldwide for water and soft drink bottles. The extensive use of PET products is justified to the material's properties, which are flexible, unbreakable, and lightweight compared to glass packaging and metal cans. PET provides high clarity, which facilitates analysis of the quality of liquid products after filling. In addition, PET holds good barrier properties against moisture and oxygen. These aspects motivate its applicability as packaging for soft drinks, mineral water, energy drinks, iced teas, juices, etc.

PET is the third most widespread polymer exploited in the packaging industry worldwide. PET bottles are responsible for the increase in solid waste, which results from economic activities based on quantity, mass production, and waste disposal. Each country seeks to develop a sustainable system for PET bottles and the best disposal alternatives for them $[17,18]$.

The post-consumer of recycled PET products has remained the point of discussion observed in several studies, as the risk of contamination concerning the packaging polymers. In addition, the decontamination efficiency in the recycling processes, as a form of reuse, has not yet been scientifically proven. This scenario occurs because there are substantial quantities of food, drinks, medicines, and other chemical products packed, stored, and transported for human consumption or use.

In 2015, there were 146 million tonnes (Mt) of plastic packaging manufactured worldwide [19]. Brazil produced 13.9 Mt of plastic packaging in the same period - about $9 \%$ of world production [20].

The collection of PET bottles starts after consumption. Among the various purposes arising from plastic waste, we highlight the following: (a) recycling of new materials arising from reprocessed and molded plastic waste; (b) reuse of PET bottles as raw material for new PET bottles; (c) use of plastic waste as a reducer for the blast furnace; and, (d) use of plastic waste for the production of coke oven oil and gas, as a source of industrial raw material [21].

Another scenario deals with technological innovations on the possibility of producing PET more sustainably from biomasses, capable of biodegrading the polyester through enzymatic processes and the action of specific and genetically modified bacteria - an alternative to PET derived from fossil sources and non-biodegradable [18]. An expectation of high recyclability of PET arises, together with the possibility of potential reuse of this material, placing hopes in the future of PET. Such technological direction derives from green chemistry, and as soon as it gains impulse and reaches its industrial expansion, it will renew the emblem of environmental viability and sustainability.

Most PET waste consists of plastic beverage bottles, and the current recycling practice is to reprocess the recovered PET bottles to produce recycled PET flakes and pellets. Reprocessing PET is expensive, and the grave concern is to remove all potential contaminants. The common problem is adhesives which decrease the quality of recycled PET [22]. This scenario sets challenges for Brazil to implement a more circular production system for the plastic packaging chain. Post-consumer plastic packaging waste streams require more attention, especially regarding the socio-productive inclusion of waste pickers [20]. Studies point CE can improve solid waste management by stimulating the developing economies, employing the principles of recovery and recycling [23].

The plastic waste remains a concern due to various adverse effects not only for human health but also for the environment (for example, pollution in the ocean, which presents a global problem). Consequently, proper management of plastic waste can contribute to the reduction of environmental impacts [20].

Brazil is one of the most global consumers of PET bottles. Therefore, its concern regarding post-consumer spreads in its plastic packaging material flow by: hybrid integration models, selective collection, and informal collection. In Brazil, 1,771 cities carry out selective collection services, corresponding to $32 \%$ of all country's cities [20].

The flow of plastic packaging in Brazil starts from the initiative of recyclable material collectors, who deliver these materials to scrap dealers to resort to recycling companies motivated by market trends and technological advances with the current applications for 
recycled PET. For example: polyester fiber for the textile industry, chemical resins, pipes, laminates, packaging, ropes, broom bristles, brushes, shower boxes, thermoforming and vacuum machines, traffic signs, and others. From the examples, the most massive market for post-consumer PET in Brazil attends the polyester fiber production for the textile industry [24].

The expanded use of the post-consumer recycled PET (as fabric fibers) may trigger a further environmental problem since the material has a short life cycle and may be disposed of inappropriately. The ideal reintegration of this material is the manufacture of other new bottles, even for non-food products, which become a more environmentally friendly production cycle. In 2019, Brazil produced 311,000 tons of post-consumer PET recycling, $12 \%$ higher than the previous year, representing $55 \%$ of the packaging discarded by consumers. From this recycled volume, $68 \%$ comes from recyclables traders, $6 \%$ from selective collection promoted by municipalities, $17 \%$ from cooperatives, 3\% from collectors, and $6 \%$ others. The recycled PET has been commercialized as granulates (43\%) and flakes (57\%) [25].

In Brazil, the difficulty in disposing of PET is related to the lack of legislation that forces industries to seek a sustainable destination for post-consumer waste. Besides legislation, government intervention through public policies is necessary to minimize the environmental impacts caused by these packages, either by raising awareness, incentives, or legal mechanisms. Intending to encourage PET recycling, the National Health Surveillance Agency (Agência Nacional de Vigilância Sanitária - ANVISA) adopted, in 2008, a resolution to reuse PET in food product packaging [17].

On the other hand, initiatives of some companies have emerged in favor of reusing and recycling PET bottles. For example, Coca-Cola Brazil implemented the same process used in the USA since the 1990s. Post-consumer bottles are separated and cleaned by an intense washing process that allows the removal of all contaminant residues. After washing, the material is prepared to enter the productive filling process. In 2008, there were also other initiatives, such as the post-consumer packages collection with the support of cooperatives. Also, there was the implementation of a project to reduce the weight of PET packaging. In that same year, the industry achieved a weight reduction of $600 \mathrm{ml}$ PET bottle from $28 \mathrm{~g}$ to $22 \mathrm{~g}$, while in the 2 -liter bottle from $52 \mathrm{~g}$ to $48 \mathrm{~g}$. This project reduced by $8,000 \mathrm{t}$ of PET weight, which collaborated to lower consumption of plastics in the PET production chain [17].

In a complementary way, the vital problem of the PET reverse chain in Brazil is the selective collection due to the lack of incentives and involvement of scrap dealers and collectors, as PET competes financially with aluminum. In other words, aluminum recycling cannibalizes the PET reverse chain. This situation forces the recycling industries to operate in an idle mode. The scarcity of collected PET hampered the sector. There is, therefore, a bottleneck in the selective collection that jeopardizes the entire reverse supply of this material to industries [17].

Thus, the Brazilian challenges in promoting CE range from improving the quality of the information system to the socio-productive inclusion of waste pickers through an effective policy of selective collection, preferably solidary [20]. Solid waste strategies should incorporate informal waste pickers into the formal management process [23].

Despite the advances in dealing with the marginalization of waste pickers in Brazil, inclusive recycling practices still need to be expanded nationwide, together with incentive mechanisms and joint actions from industry entities and public agencies (regulating or promoting public policies) [20].

We noticed that, in Brazil, there is still a gap between the consumption of PET packaging (principally bottles) and the recycling capacity. It occurs due to the lack of effective investments, public awareness, and stimuli to collectors and scrap dealers - who are the main drivers to consolidate solid waste management.

\section{Consumers' purchase intention for recycled products}


Empirical studies on environmentally conscious consumption state that the intention to purchase does not necessarily legitimate the purchase. Although the growth of consumers with favorable attitudes for sustainable products, there wasn't a purchased increase of these types of products [26, 27].

Principally to fashion items, although consumers tend to be increasingly concerned with sustainable consumption, this attitude does not translate into real behavior [28]. Being the largest post-consumption market in Brazil, the textile industry - that contributes to the recycling of PET bottles - faces a scenario that still needs to be demystified.

Purchasing decisions of sustainable products need to be better understood since it is a process that typically incorporates several motivations that interfere with the choice. Some studies have attempted to recognize this link between ethical principles and antecedent behavioral factors. However, ethics may be secondary to other decision factors. In this case, it can be related to a perceived conflict between making sustainable choices and fashion consumption itself $[28,29]$. As much as people show favorable to sustainable consumption, in practice, they are not in their entirety, as can be demonstrated in the mentioned studies about fashion. In that example, recycled clothing products are not presented as potential consumption factors in circumstances of choices.

Therefore, individual characteristics related to personal conditions, which cause dilemmas between consumption decisions and environmental issues. The perception of consumer effectiveness to sustainability issues needs to be understood concerning green behavior [30]. Other studies have found some consumers prefer not to purchase green products due to perceived risks, like price, quality, and availability [31, 32]. Thus, high prices and low quality, beyond the lack of availability or limited variety in stores, make up blockade factors for green shopping.

On the other hand, attitudes and habits comprise the most critical factors in determining green consumption, while knowledge about sustainability or recycling had only moderate effects [33]. For the authors, environmental education may remain a key factor (with direct and indirect effects) to lead to a greater willingness and engagement for sustainable consumption.

Environmental education makes it possible to increase the general awareness level of the population, added to other public and private measures (like infrastructure, legislation, and waste tracking), it becomes crucial to awakening a more sustainable consumption and, also, maximize resource efficiency through recycling [34].

In a way, environmental education provides consumers with a sustainable understanding and does not promote the belief that recycling should consider product quality as a factor in the purchase decision. When consumers' concerns about the environment increase, they are likely to relate this fact to a more environmentally friendly position [35].

Promoting CE and, at the same time, reducing global warming are part of the sustainable and ecological issues, present an increasingly significant challenge in society. Therefore, society (as well as companies, industries, and governments) needs to mobilize itself through environmental education - all in a coordinated way. On the one hand, companies and industries seek sustainability and environmental projects concerned with their business continuity. On the other hand, the diffusion of environmental awareness among all agents of the chain is required, and it must be self-stimulated, guided by the government to the effectiveness of the CE.

\section{Research Hypotheses}

The research hypotheses of this study were adapted from [4] model to replicate and extend their model and testing its generalizability. The purpose was to scrutinize whether post-consumer recycled PET products positively affect consumers' purchase intentions, seeking to understand which relationship satisfies propositional conditions for CE. Moreover, it is expected to test the generalizability of models created for use in developing economies like the Brazilian context. The hypotheses are as follows:

H1: the quality of recycled products negatively influences the intention to purchase; 
The perception of low quality of recycled products reduces the willingness and purchase preference of the consumers if compared to new products. Therefore, it is necessary to make recycled products attractive enough to offset the low-quality bias to compete with new goods in the marketplace [36, 37, 38].

$\mathrm{H} 2$ : the image of recycled products positively influences the intention to purchase;

The concern with the consumption of environmentally friendly products (known as "green products") may contribute to consumers project a positive image for recycled products. This attitude can reduce waste, reuse discarded material and demand less energy. I.e., a good product image can change consumer behavior and contribute to a broader acceptance of recycled products [39].

H3: the sustainability of recycled products positively influences the intention to purchase;

Consumers concerned about sustainability issues may be willing to accept recycled products and, therefore, are likely to purchase recycled products, especially when they are aware of the associated environmental benefits $[38,40]$.

$\mathrm{H} 4$ : the perceived safety of recycled products negatively influences the intention to purchase.

In the view of some consumers of recycled products, the purchase of the recycled products brings risks, uncertainty, and insecurity. These issues involve numerous aspects such as discouragement in manufacture recycled products; lack of experience with consumption of recycled products; lack of knowledge about the safety of recycled products; and, the possibility of contamination. Consequently, recycled products can produce a negative impact on perceived safety, adversely influencing the buying process.

\section{Methods}

This work adopted a quantitative approach through an exploratory-descriptive research nature. The aim was to collect data from the response of individuals (research participants) for subsequent statistical treatment. We used the research model developed by [4], initially applied in Spain. The questionnaire was composed of two blocks. The first consists of questions concerning the respondent's profile. The second consists of assertions that address the variables of analysis.

Two English native speakers translated the questionnaire. Next, experts on the subject support the cross-cultural adaptation process and the content validity of the questionnaire. We applied a pre-test to verify the need for questionnaire adaptation, language adequacy, and understanding of the used expressions. For semantic validity, we utilized people of the target population of the study.

From a quantitative approach, partial least squares structural equation modeling (PLS-SEM) was the method applied to test the hypotheses of causality between the variables - utilizing the software SmartPLS version 3.3.3. Latent variables cover the 14 indicators reported in Table 2, based on a 5-point Likert scale to determine the level of agreement (Strongly Disagree to Strongly Agree).

Table 2. Variables and indicators used in the research.

\begin{tabular}{c|l|l}
\hline \multirow{1}{*}{$\begin{array}{c}\text { Construct } \\
\text { (Latent Variable) }\end{array}$} & \multicolumn{2}{c}{ Indicators } \\
\hline \multirow{4}{*}{ Perceived Quality } & Qual1 & Recycled products have good quality \\
\cline { 2 - 3 } & Qual2 & Recycled products give me the quality that I expect \\
\cline { 2 - 3 } & Qual3 & $\begin{array}{l}\text { Recycled products have a quality similar to that of products that are not sus- } \\
\text { tainable }\end{array}$ \\
\hline \multirow{4}{*}{ Product Image } & Img1 & I have a positive image of recycled products \\
\cline { 2 - 3 } & Img2 & Consumers of recycled products know how to buy (buy intelligently) \\
\cline { 2 - 3 } & Img3 & Recycled products have a positive/favorable image in the market \\
\hline
\end{tabular}




\begin{tabular}{l|c|l} 
Sustainability / Envi- & Sust1 & Recycled products respect the environment/are good for the environment \\
\cline { 2 - 3 } ronmental benefits & Sust2 & Recycled products offer significant environmental benefits \\
\hline \multirow{4}{*}{ Safety } & Saf1 & Recycled products are safe for consumers \\
\cline { 2 - 3 } & Saf2 & The production process of recycled products is safe and reliable \\
\cline { 2 - 3 } & Saf3 & Recycled products are benign and no harmful \\
\hline \multirow{4}{*}{ Intention to Purchase } & Int1 & I will buy recycled products in the future \\
\cline { 2 - 3 } & Int2 & I am likely to buy recycled products \\
\cline { 2 - 3 } & Int3 & I will continue buying recycled products \\
\hline
\end{tabular}

Source: Based on [4].

The study used a convenience (non-probabilistic) sampling method. Data collection occurred between June and July 2021 in Brazil. An online questionnaire (Google Forms) was sent by e-mail and WhatsApp messages. The target audience was primarily undergraduate and graduate students and professors of higher education in Brazil, totaling a sample of 435 respondents, 422 of which were considered valid. Since this is a new subject, [4] used an introductory text to contextualize the subject matter. In this study, applications for recycled PET were presented as an introductory text in the questionnaire.

It was informed to the respondents that several sectors of the economy use products that contain recycled PET. For example, the textile and clothing industry produces blankets, quilts, and sweatshirts with recycled PET. Other examples include office and school supplies (rulers, pens, and pencil holders) or packaging and utensils for cleaning and food (brooms, buckets, clotheslines, and gardening equipment). Recycled PET is also utilized in civil construction (like water tanks, pipes, fittings, taps, swimming pools, roof tiles, inks, paints, and varnishes) and in the automobile industry (like carpet coverings, bumpers, cabin parts, and aerodynamic elements) [25].

\section{Results}

\subsection{Profile of the participants}

Women represented $54.3 \%$ of the participants. Regarding education, $85.8 \%$ of the people had at least the higher education degree. Considering the sum of participants who had completed higher education: $48.1 \%$ made specialization, and $37.7 \%$ completed the master's degree or the doctorate.

Concerning family income, $55.2 \%$ of the participants earn less than $\mathrm{R} \$ 15,000.00$. The survey included participants from all country's regions, with the majority from the Southeast $(36.7 \%)$, followed by the Northeast $(27.7 \%)$. The average age of the participants was 38 years old, with a predominance of people between 25 and 40 years old $(49.1 \%)$, followed by people between 40 and 55 years old $(23.9 \%)$. The details of the participants are in Table 3.

Table 3. Profile of the participants.

\begin{tabular}{l|l|r|r|r}
\hline \multicolumn{2}{l|}{ Variable } & Frequency & Percentage (\%) & $\begin{array}{c}\text { Accumulated } \\
\text { Percentage (\%) }\end{array}$ \\
\hline \multirow{2}{*}{ Gender } & Female & 229 & 54.3 & 54.3 \\
& Male & 193 & 45.7 & 100.0 \\
\hline \multirow{5}{*}{ Education Level } & 2 & .5 & .5 \\
& Elementary School Complete & 8 & 1.9 & 2.4 \\
& High School Complete & 50 & 11.8 & 14.2 \\
& Higher Education incomplete & 203 & 48.1 & 62.3 \\
\hline
\end{tabular}




\begin{tabular}{|c|c|c|c|c|}
\hline & $\begin{array}{l}\text { Graduate Education complete } \\
\text { (Specialisation, Master's de- } \\
\text { gree, Doctorate) }\end{array}$ & 159 & 37.7 & 100.0 \\
\hline \multirow{5}{*}{ Income ${ }^{*}$} & Up to $R \$ 1,000.00$ & 8 & 1.9 & 1.9 \\
\hline & From $\mathrm{R} \$ 1,000.00$ to $\mathrm{R} \$ 5,000.00$ & 115 & 27.3 & 29.1 \\
\hline & $\begin{array}{l}\text { From } \mathrm{R} \$ 10,000.00 \text { to } \mathrm{R} \$ \\
15,000.00\end{array}$ & 110 & 26.1 & 55.2 \\
\hline & $\begin{array}{l}\text { From } \mathrm{R} \$ 5,000,00 \text { to } \mathrm{R} \$ \\
10,000,00\end{array}$ & 117 & 27.7 & 82.9 \\
\hline & Over $\mathrm{R} \$ 15,000.00$ & 72 & 17.1 & 100.0 \\
\hline \multirow{5}{*}{ Regions of Brazil } & Central-West & 28 & 6.6 & 6.6 \\
\hline & Northeast & 117 & 27.7 & 34.4 \\
\hline & North & 26 & 6.2 & 40.5 \\
\hline & Southeast & 155 & 36.7 & 77.3 \\
\hline & South & 96 & 22.7 & 100.0 \\
\hline \multirow{4}{*}{ Age } & Up to 25 years old & 60 & 14.2 & 14.2 \\
\hline & From 25 to 40 years old & 207 & 49.1 & 63.3 \\
\hline & From 40 to 55 years old & 101 & 23.9 & 87.2 \\
\hline & Over 55 years old & 54 & 12.8 & 100.0 \\
\hline
\end{tabular}

Source: Research data, 2021. Notes. ${ }^{*} \mathrm{R} \$ 1.00$ (Real) is equivalent to US\$ 0.19 (USD), in august 2021.

\subsection{Descriptive statistics of the indicators}

Regarding the descriptive statistics of the indicators used in the research (see Table 4), the latent variables Perceived Quality (Qual1, Qual2, Qual3) and Intention to Purchase (Int1, Int2, Int3) had the lowest mean, mode, and median - values close to 2 (two). The result indicates most participants demonstrate low agreement with the quality of recycled products and the intention to purchase these products.

The other indicators presented values for mean, mode, and median close to 4 (four), pointing to the agreement with the statements in the questionnaire. However, the descriptive statistics are insufficient for include variables in the model, and issues regarding quality and reliability need to be analyzed.

Table 4. Descriptive Statistics.

\begin{tabular}{l|c|c|c|c|c|c|c}
\hline \multicolumn{1}{c|}{ Latent Variable } & Id & Mean & Median & Mode & $\begin{array}{c}\text { Standard } \\
\text { Deviation }\end{array}$ & Minimum & Maximum \\
\hline \multirow{3}{*}{ 1. Perceived Quality } & Qual1 & 2.06 & 2 & 2 & 0.54 & 1 & 4 \\
& Qual2 & 2.12 & 2 & 2 & 0.60 & 1 & 4 \\
& Qual3 & 2.50 & 2 & 3 & 0.72 & 5 \\
\hline \multirow{2}{*}{ 2. Product Image } & Img1 & 3.86 & 4 & 4 & 0.73 & 2 & 5 \\
& Img2 & 3.93 & 4 & 4 & 0.61 & 3 & 5 \\
\hline \multirow{2}{*}{ 3. Sustainability } & Img3 & 3.87 & 4 & 4 & 0.61 & 5 & 5 \\
\hline 4. Safety & Sust1 & 3.91 & 4 & 4 & 0.53 & 2 & 5 \\
\hline
\end{tabular}




\begin{tabular}{l|c|c|c|c|c|c|c}
\hline & Saf2 & 3.93 & 4 & 4 & 0.58 & 3 & 5 \\
& Saf3 & 3.41 & 3 & 3 & 0.67 & 1 & 5 \\
\hline \multirow{3}{*}{5. Intention to Purchase } & Int1 & 2.14 & 2 & 2 & 0.59 & 1 & 5 \\
\cline { 2 - 8 } & Int2 & 2.18 & 2 & 2 & 0.60 & 1 & 4 \\
\cline { 2 - 8 } & Int3 & 2.27 & 2 & 2 & 0.68 & 1 & 5 \\
\hline
\end{tabular}

Source: Research data, 2021.

\subsection{Evaluation of the Measurement Model}

Initially, the model evaluation focuses on the measurement model, which defines how the constructs or latent variables are operationalized by the observed variables. Therefore, convergent validity, reliability, and discriminant validity were assessed.

For the convergent validity, indicators with factor loadings lower than 0.708 should be removed from the model because they influence the value of the average variance extracted (AVE) - that should be greater than 0.5 [41]. The variables Qual3 and Int3 left the model because they had factor loadings of 0.620 and 0.466 , respectively. All other indicators showed factor loadings above the minimum desired value and, therefore, the average variances extracted from the latent variables were equally above the reference value (see Table 5).

Table 5. Criteria related to Convergent Validity and Internal Consistency.

\begin{tabular}{l|c|c|c|c}
\hline \multicolumn{1}{c|}{ Latent Variable } & Cronbach's Alpha & p-rho_A & $\begin{array}{c}\text { Composite } \\
\text { Reliability }\end{array}$ & AVE \\
\hline Perceived Quality & 0.853 & 0.905 & 0.930 & 0.870 \\
\hline Product Image & 0.854 & 0.855 & 0.912 & 0.775 \\
\hline Sustainability & 0.835 & 0.835 & 0.924 & 0.858 \\
\hline Safety & 0.801 & 0.826 & 0.882 & 0.715 \\
\hline Intention to Purchase & 0.821 & 0.822 & 0.918 & 0.848 \\
\hline
\end{tabular}

Source: Research data, 2021.

Table 5 also verifies the internal consistency by Cronbach's alpha, Dillon Goldestein's p-rho, and Composite Reliability, which it can be noted that the values are above the reference limit (0.7).

The discriminant validity consists of the degree to which a measure does not correlate with other measures that it is supposed to diverge [42]. The cross-loadings confirmed they presented more significant factorial loadings in their respective latent variables than in others [43], as shown in Table 6. Furthermore, the square root of the AVE for each variable should be greater than the correlations of the constructs and once the model is considered reliable and valid, one should next proceed with the analysis of the structural model [41, $44]$.

Table 6. Correlation Coefficients and Discriminant Validity.

\begin{tabular}{l|c|c|c|c|c}
\hline \multicolumn{1}{c|}{ Latent Variable (Construct) } & $\mathbf{1}$ & $\mathbf{2}$ & $\mathbf{3}$ & $\mathbf{4}$ & $\mathbf{5}$ \\
\hline 1. Product Image & $\mathbf{0 , 8 8}$ & & & & \\
2. Intention to Purchase & 0.75 & $\mathbf{0 . 9 2}$ & & & \\
3. Perceived Quality & -0.75 & -0.75 & $\mathbf{0 . 9 3}$ & & \\
4. Safety & -0.68 & -0.76 & 0.73 & $\mathbf{0 . 8 4}$ & \\
5. Sustainability & 0.74 & 0.80 & -0.72 & -0.72 & $\mathbf{0 . 9 2}$ \\
\hline
\end{tabular}

Source: Research data, 2021. Note. Correlations between the latent variables are outside of the diagonals. Bold numbers on the diagonal correspond to the square roots of the AVE for each construct. 


\subsection{Structural Model}

The multicollinearity of the variables was evaluated, considering the path coefficients may be biased if the estimate involves significant levels of collinearity between the predictor constructs. All indicators presented variance inflation factor (VIF) values between 1.5 and 2.8. Among the latent variables, the values were between 2.9 and 3.1, indicating a poor correlation between them, so it is comprehended that the criterion was satisfied (see Table 7).

Table 7. Evaluation of the Structural Model.

\begin{tabular}{l|c|cc|c}
\hline \multicolumn{1}{c|}{ Latent Variable } & VIF & Confidence interval & $\mathbf{f}^{2}$ \\
\hline Perceived Quality & 3.017 & -0.283 & -0.043 & 0.036 \\
Product Image & 2.895 & 0.049 & 0.284 & 0.044 \\
Sustainability & 2.943 & 0.258 & 0.488 & 0.182 \\
Safety & 2.678 & -0.400 & -0.141 & 0.100 \\
\hline
\end{tabular}

Source: Research data, 2021.

In Table 7 , it was also analyzed the effect size $\left(\mathrm{f}^{2}\right)$, which evaluates the relative importance of each construct in the model [45]. Like so, the values obtained: between Intention to Purchase and Perceived Quality was 0.036; between Intention to Purchase and Product Image was 0.044; and between Intention to Purchase and Safety was 0.10 - all considered poor. Between Intention to Purchase and Sustainability was 0.182, which is considered medium. According to the p-values, it is notable the coefficients are significant at the 5\% level. Therefore, all the hypotheses were validated. A measure of the predictive accuracy, which represents the combined effects of the exogenous latent variables on the endogenous latent variable, is obtained by analyzing the $\mathrm{R}^{2}$ and adjusted $\mathrm{R}^{2}$ values for the Intention to Purchase $(0.750 ; 0.748)$, suggesting a substantial effect. Finally, regarding the redundancy of the constructs, as the $\mathrm{Q}^{2}$ value was higher than zero $(0.626)$, the adjusted model maintains a considerable degree of predictive relevance [45].

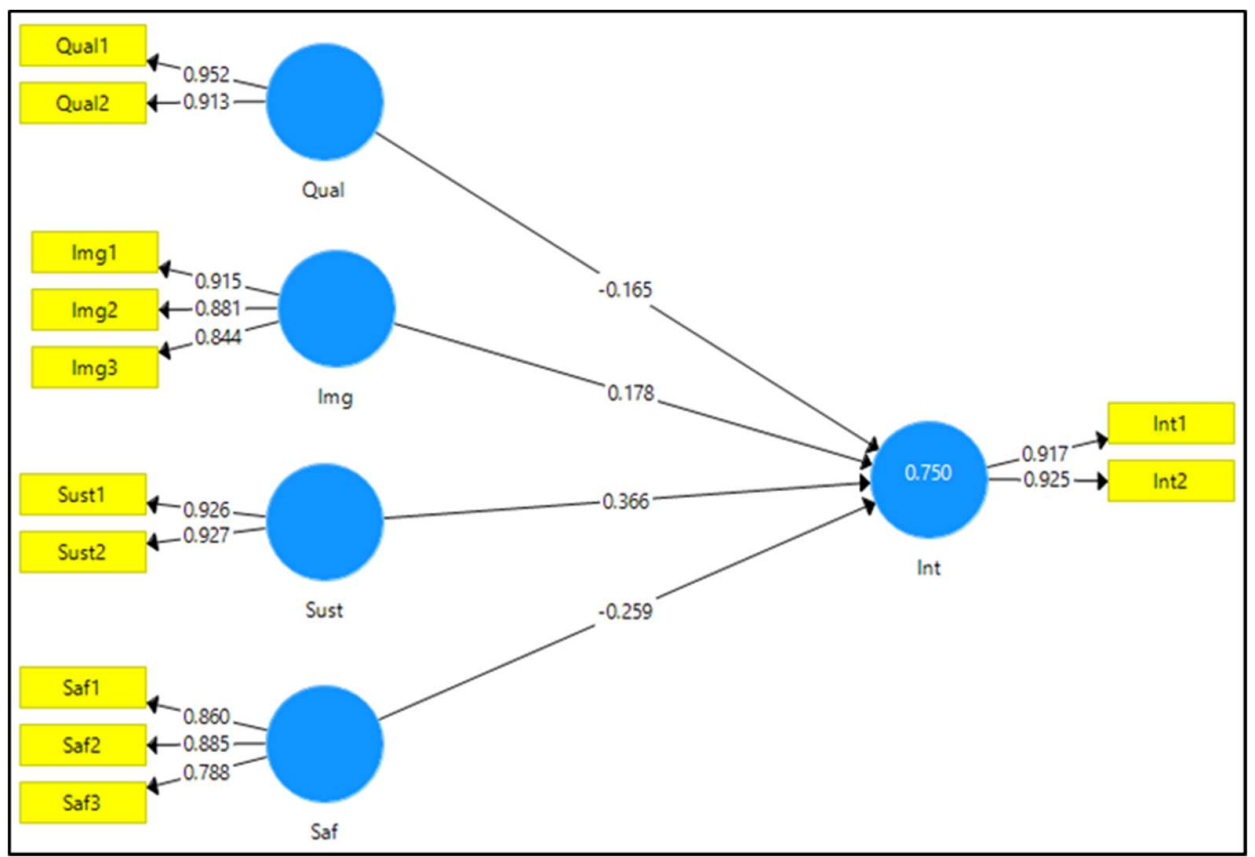

Figure 2. Measurement and Structural Model. 
The results indicate that all hypotheses were accepted, presenting $t$ values $>1.96$ and $\mathrm{p}<0.05$ for a significance level of $5 \%$. Figure 2 details the analysis for each hypothesis, which highlights:

$\mathrm{H} 1$ : the quality of recycled products negatively influences the intention to purchase;

The consumers' perception about the quality of the recycled products has negatively influenced the intention to purchase intention (path coefficient $=-0.165$ ). Different from the results found in Spain [4], but corroborating with the result from the research in $\mathrm{Vi}$ etnam [12]. Therefore, the perception of low quality on the recycled products reduces consumers' purchase intentions, requiring strategies to diminish or eliminate the prejudice about the low quality associated with products made of discarded materials, and, thus, to increase the production of recycled goods.

$\mathrm{H} 2$ : the image of recycled products positively influences the intention to purchase;

In Brazil, the recycled products image positively affects purchase intention, as per the results found in Spain. In the results found in Vietnam, this relationship was not evident.

H3: the sustainability of recycled products positively influences the intention to purchase;

As proposed in the original model, Brazilian consumers are aware of the environmental benefits provided by recycled products and are inclined to purchase these products. This hypothesis was unaccepted in the research applied in Spain, but it was observed in Vietnam. It is worth mentioning that the path coefficient (0.366) evidences that this is the most relevant construct that determines the intention to purchase.

H4: the perceived safety of recycled products negatively influences the intention to purchase.

Recycled products demonstrate a negative impact on perceived safety, which negatively influences the purchase process of recycled products in Brazil - we observed that the path coefficient $(-0.259)$ is the second in terms of magnitude.

\section{Discussion}

The path coefficients analysis represents the hypothetical relations between the constructs, with standardized values between -1 and +1 (values close to +1 represent strong positive relations). These coefficients demonstrate similarities with other traditional regression models, but additionally, they present structural relations. In Table 8, it is possible to notice that the highest link is between sustainability and intention to purchase (0.366). On the other hand, the relationships between perceived quality and intention to purchase and between sustainability and intention to purchase are negative.

Table 8. Results of Significance Test of Path Coefficients.

\begin{tabular}{l|c|c|c|c}
\hline \multicolumn{1}{c|}{ Relationship between the constructs } & $\begin{array}{c}\text { Path } \\
\text { Coefficients }\end{array}$ & t-test & p-value & $\begin{array}{c}\text { Hypothesis } \\
\text { Testing }\end{array}$ \\
\hline Perceived Quality -> Intention to Purchase & -0.165 & 2.735 & 0.006 & H1: Accepted \\
Image -> Intention to Purchase & 0.178 & 3.023 & 0.003 & H2: Accepted \\
Sustainability -> Intention to Purchase & 0.366 & 6.285 & 0.000 & H3: Accepted \\
Safety -> Intention to Purchase & -0.259 & 3.877 & 0.000 & H4: Accepted \\
\hline
\end{tabular}

Source: Research data, 2021.

From all the analyses and the results, Figure 2 presents the measurement and structural model.

\section{Conclusions}

Similar to the model proposed by [4], in our study, the perceived quality, the image, the sustainability/environmental benefits, and the safety of recycled products comprised 
factors influencing the intention of Brazilian consumers to purchase recycled PET products.

Unlike the results achieved in samples from Spain and Vietnam [4, 12], the model validated here with Brazilian consumers (considering all regions of the country, mostly women, with an average age of 38 years, high education complete, and income of approximately $\mathrm{R} \$ 15,000.00)$ confirmed the four research hypotheses: H1 - the quality of recycled products negatively influences the intention to purchase; H2 - the image of recycled products positively influences the intention to purchase; H3 - the sustainability of recycled products positively influences the intention to purchase; $\mathrm{H} 4$ - the safety perception of recycled products negatively influences the intention to purchase.

The purchase intention confirms the importance of quality, image, sustainability, and safety derived from the post-consumer recycled PET products, as found in this research. Beyond this result, the synergy is relevant to the entire post-consumer PET chain [17, 20]. The lack of stimulus can obstruct the socio-productive inclusion by the involvement of scrap dealers and collectors. I.e., we understood as critical factors in the supply chain and effectuation of the CE cycle. To a certain extent, perceptions or consumption intentions of recycled PET products released from the CE are not enough. Although the positive consumption reactions, it is necessary to improve solid waste management driving agents involved with waste recovery and recycling. At the same time, programs and joint actions of sector entities and public agencies need incentives [20,23].

Furthermore, corroborating the theoretical treatment established in [33, 34, 35], the findings of this study demonstrate that for the CE to become effective, environmental education becomes necessary as an elementary factor, since it attributes a relevant role to the engagement for sustainable consumption.

Based on the hypotheses confirmation, one must consider the necessity for investments in production plans and marketing strategies for recycling companies. These investments could cooperate with the quality and safety of recycled products, modifying over time the view of many consumers that these products present inferior quality and are harmful to health and safety, as demonstrated by the negative correlations between these variables and the intention to purchase. By validating the factors that promote the purchase intention of recycled products, this study may inspire further empirical research concerning CE in Brazil and its unfolding concerning reduction, reuse, and recycling, which contribute to the circular business models.

For future works, we suggest including variables that relate to the price of recycled products as one of the determinants of purchase intention. In addition, the use of other types of recycled products and the modification of the target audience research (especially people with lower income) are preferable.

Supplementary Materials: The following are available online at www.mdpi.com/xxx/s1, Figure S1: title, Table S1: title, Video S1: title.

Author Contributions: “Conceptualization, Fernanda Cristina Barbosa Pereira Queiroz and Nilton Cesar Lima; investigation, Fernanda Cristina Barbosa Pereira Queiroz, Nilton Cesar Lima, Christian Luiz da Silva, Jamer-son Viegas Queiroz and Gustavo Henrique Silva de Souza; methodology, Fernanda Cristina Barbosa Pereira Queiroz; software, Fernanda Cristina Barbosa Pereira Queiroz; validation, Fernanda Cristina Barbosa Pereira Queiroz, Jamerson Viegas Queiroz and Christian Luiz da Silva; formal analysis, Nilton Cesar Lima and Gustavo Henrique Silva de Souza; resources, Fernanda Cristina Barbosa Pereira Queiroz, Nilton Cesar Lima, Christian Luiz da Silva, Jamerson Viegas Queiroz and Gustavo Henrique Silva de Souza; data curation Fernanda Cristina Barbosa Pereira Queiroz; writing - original draft preparation, Fernanda Cristina Barbosa Pereira Queiroz, Nilton Cesar Lima, Christian Luiz da Silva, Jamerson Viegas Queiroz and Gustavo Henrique Silva de Souza; writing - review and editing, Nilton Cesar Lima, Christian Luiz da Silva; visualization, Jamerson Viegas Queiroz; supervision, Fernanda Cristina Barbosa Pereira Queiroz; project administration, Fernanda Cristina Barbosa Pereira Queiroz and Christian Luiz da Silva; All authors have read and agreed to the published version of the manuscript." 
Funding: Please add: “This research received no external funding".

Data Availability Statement: The datasets generated for this study are available on request to the corresponding author.

Conflicts of Interest: The authors declare no conflict of interest.

\section{References}

1. Silva, C.L. Política pública para o planejamento urbano territorial a partir da economia circular: reflexões e alinhamentos propositivos para as cidades brasileiras. Revista Brasileira de Gestão e Desenvolvimento Regional. 2019, 15, 159-165. Available online: https://www.rbgdr.net/revista/index.php/rbgdr/article/view/5192. Accessed on: 21/07/2021.

2. Fundação Ellen Macarthur. Economia Circular. 2020. Available online: https://archive.ellenmacarthurfoundation.org. Accessed on: 30/07/2020.

3. Bradley, R.; Jawahir, I.S.; Badurdeen, F.; Rouch, K. A total life cycle cost model (TLCCM) for the circular economy and its application to post-recovery resource allocation. Resources, Conservation $\mathcal{E}$ Recycling. 2018, 135, 141-49. DOI: https://doi.org/10.1016/j.resconrec.2018.01.017.

4. Calvo-Porral, C.; Lévy-Mangin, J.P. The circular economy business model: examining consumers' acceptance of recycled goods. Administrative Sciences. 2020, 10, 1-13. DOI: https://doi.org/10.3390/admsci10020028.

5. De Angelis, R. Business models in the circular economy: concepts, examples and theory. Springer, 2018; pp. 11-43. DOI: https://doi.org/10.1007/978-3-319-75127-6_2.

6. Nobre, G.C.; Tavares, E. The quest for a circular economy final definition: a scientific perspective. Journal of Cleaner Production. 2021, 314, 127973. DOI: https://doi.org/10.1016/j.jclepro.2021.127973.

7. Ghisellini, P.; Cialani, C.; Ulgiati, S. A review on circular economy: the expected transition to a balanced interplay of environmental and economic systems. Journal of Cleaner Production. 2016, 114, 11-32. DOI: https://doi.org/10.1016/j.jclepro.2015.09.007.

8. Brennan, G.; Tennant M.; Blomsma. F. Business and production solutions: closing loops and the circular economy. Edited by Helen Kopnina and John Blewitt. London: Routledge, 2015; pp. 218-245.

9. Corvellec, H.; Böhm, S.; Stowell, A.; Valenzuela, F. Introduction to the special issue on the contested realities of the circular economy. Culture and Organization. 2020, 26, 2, 97-102. DOI: https://doi.org/10.1080/14759551.2020.1717733.

10. Kirchherr, J.; Van Santen, R. Research on the circular economy: A critique of the field. Resources, Conservation E Recycling. 2019, 151, 2-3. DOI: https://doi.org/10.1016/j.resconrec.2019.104480.

11. Murray, A.; Skene, K.; Haynes, K. The circular economy: an interdisciplinary exploration of the concept and application in a global context. Journal of Business Ethics. 2017, 1, 369-380.

12. Luu, T.T.A.; Baker, J.R. Exploring Consumers' Purchase Intention of PET bottle-based apparel in an emerging economy. Administrative Sciences. 2021, 7, 1-12. DOI: https://doi.org/10.3390/joitmc7010022.

13. Stahel, W.R. The circular economy. Nature. 2016, 531, 435-438. DOI: https://doi.org/10.1038/531435a.

14. Ghisellini, P.; Ji, X.; Liu, G.; Ulgiati, S. Evaluating the transition towards cleaner production in the construction and demolition sector of China: A review. Journal of Cleaner Production. 2018, 195, 418-434. DOI: https://doi.org/10.1016/j.jclepro.2018.05.084.

15. Kirchherr, J.; Reike, D.; Hekkert, M. Conceptualizing the circular economy: an analysis of 114 definitions. Resources, Conservation and Recycling. 2017, 127, 221-232. DOI: https://doi.org/10.1016/j.resconrec.2017.09.005.

16. Arruda, E.H.; Melatto, R.A.P.B.; Levy, W.; Conti, D.M. Circular economy: A brief literature review (2015-2020). Sustainable Operations and Computers. 2021, 2, 79-86. DOI: https://doi.org/10.1016/j.susoc.2021.05.001.

17. Coelho, T.M.; Castro, R.; Gobbo Jr., J.A. PET containers in Brazil: opportunities and challenges of a logistics model for postconsumer waste recycling. Resources, Conservation and Recycling. 2011, 55, 291-299. DOI: https://doi.org/10.1016/j.resconrec.2010.10.010.

18. Nisticò, R. Polyethylene terephthalate (PET) in the packaging industry. Polymer Testing. 2020, 90, 106707. DOI: https://doi.org/10.1016/j.polymertesting.2020.106707.

19. Geyer, R.; Jambeck, J.R.; Law, K.L. Production, use, and fate of all plastics ever made. Science Advances. 2017, 3, e1700782. DOI: https://doi.org/10.1126/sciadv.1700782.

20. Pincelli, I.P.; Castilhos, A.B.; Matias, M.S.; Rutkowski, E.W. Post-consumer plastic packaging waste flow analysis for Brazil: the challenges moving towards a circular economy. Waste Management. 2021, 126, 781-790. DOI: https://doi.org/10.1016/j.wasman.2021.04.005.

21. Kawamoto, K. Waste recycling technologies required by a sound material-cycle society. Quaterly Review. 2008, 27. Available online: https://core.ac.uk/reader/236667460. Accessed on: 14/06/2021.

22. Li, Y.; White, D.J.; Peyton, R.L. Composite material from fly ash and post-consumer PET. Journal Resources, Conservation and Recycling. 1998, 24, 87-93. DOI: https://doi.org/10.1016/S0921-3449(98)00041-X.

23. Ferronato, N.; Rada, E.C.; Portillo, M.A.G.; Cioca, L.I.; Ragazzi, M.; Torretta, V. Introduction of the circular economy within developing regions: a comparative analysis of advantages and opportunities for waste valorization. Journal of Environmental Management. 2019, 230, 366-378. DOI: https://doi.org/10.1016/j.jenvman.2018.09.095.

24. Cempre - Compromisso Empresarial para a Reciclagem. 2021. Available online: http://www.cempre.org.br. Accessed on: $18 / 06 / 2021$. 
25. Abipet - Associação Brasileira dos Fabricantes de Embalagens PET. Reciclagem de Embalagens PET. Available online: http://www.abipet.com.br. Accessed on: 18/06/2021.

26. Morwitz, V.G.; Steckel, J.H.; Gupta, A. When do purchase intentions predict sales? International Journal of Forecasting. 2007, 23, 347-364. DOI: https://doi.org/10.1016/j.ijforecast.2007.05.015.

27. Park, H.J.; Lin, L.M. Exploring attitude-behavior gap in sustainable consumption: comparison of recycled and upcycled fashion products. Journal of Business Research. 2020, 117, 623-628. DOI: https://doi.org/10.1016/j.jbusres.2018.08.025.

28. Mcneill, L.; Moore, R. Sustainable fashion consumption and the fast fashion conundrum: Fashionable consumers and attitudes to sustainability in clothing choice. International Journal of Consumer Studies. 2015, 39, 212-222. DOI https://doi.org/10.1111/ijcs.12169.

29. Bray, J.; Johns, N.; Kilburn, D. An exploratory study into the factors impeding ethical consumption. Journal of Business Ethics. 2011, 98, 597-608. DOI: https://doi.org/10.1007/s10551-010-0640-9.

30. Gupta, S.; Ogden, D.T. To buy or not to buy? A social dilemma perspective on green buying. Journal of Consumer Marketing. 2009, 26, 376-391. DOI: https://doi.org/10.1108/07363760910988201.

31. Connell, K.Y.H. Internal and external barriers to eco-conscious apparel acquisition. International Journal of Consumer Studies. 2010, 34, 279-286. DOI: https://doi.org/10.1111/j.1470-6431.2010.00865.x.

32. Kim, S.Y.; Rha, J.Y. How consumers differently perceive about green market environments: across different consumer groups in green attitude-behaviour dimension. International Journal of Human Ecology. 2014, 15, 43-57. DOI: https://doi.org/10.6115/ijhe.2014.15.2.43.

33. Islam, M.T.; Dias, P.; Huda, N. Young consumer's e-waste awareness, consumption, disposal, and recycling behavior: A case study of university students in Sydney, Australia. Journal of Cleaner Production. 2021, 282, 124490. DOI: https://doi.org/10.1016/j.jclepro.2020.124490.

34. Dias, P.; Bernardes, A.M.; Huda, N. Ensuring best e-waste recycling practices in developed countries: an Australian example. Journal of Cleaner Production. 2019, 209, 846-854. DOI: https://doi.org/10.1016/j.jclepro.2018.10.306.

35. Adigüzel, F.; Donato, C. Proud to be sustainable: Upcycled versus recycled luxury products. Journal of Business Research. 2021, 130, 137-146. DOI: https://doi.org/10.1016/j.jbusres.2021.03.033.

36. Lin, C.; Chang A.C.A. Double standard: The role of environmental consciousness in green product usage. Journal of Marketing. 2012, 76, 125-34. DOI: https://doi.org/10.1509/jm.11.0264.

37. Singh, J.; Ordoñez, I. Resource recovery from post-consumer waste: important lessons for the upcoming circular economy. Journal of Cleaner Production. 2016, 134, 342-353. DOI: https://doi.org/10.1016/j.jclepro.2015.12.020.

38. Wang, Y.; Wiegerinck, V.; Krikke H.; Zhang, H. Understanding the purchase intention towards remanufactured product in closed-loop supply chains. International Journal of Physical Distribution \& Logistics Management. 2013, 43, 866-88. DOI: https://doi.org/10.1108/IJPDLM-01-2013-0011.

39. Tsen, C.; Phang G.; Hasan H.; Buncha M.R. Going green: A study of consumers' willingness to pay for green products in Kota Kinabalu. International Journal of Business and Society. 2006, 7, 40-54.

40. Hazen, B.T.; Mollenkopf, D.A.; Wang, Y. Remanufacturing for the Circular Economy: an examination of consumer switching behavior. Business Strategy and the Environment. 2016, 26, 451-464. DOI: https://doi.org/10.1002/bse.1929.

41. Hair, J.F.; Hult, T.M.; Ringle, C.M.; Sarstedt, M. A Primer on Partial Least Squares Structural Equation Modeling (PLS-SEM). Los Angeles: SAGE, 2014; pp. 01-307.

42. Sánchez, M.; Sarabia, F.J. Validez y fiabilidad de escalas. In: SARABIA, F. J. (Coord.), Metodologia para la investigación em marketing y dirección de empresas, Madrid, Editorial Pirámide, 1999; pp. 363-393.

43. Chin, W.W. The partial least squares approach for structural equation modeling. In Marcoulides, G.A. (Ed.). Modern methods for business research. London: Lawrence Erlbaum Associates, 1998; pp. 295-236.

44. Fornell, C.; Larcker, D. Structural equation models with unobservable variables and measurement error: algebra and statistics. Journal of Marketing Research. 1981, 18, 328-388.

45. Ringle, C.M.; Silva, D.; Bido, D. Modelagem de Equações Estruturais com Utilização do SMARTPLS. Revista Brasileira de Marketing - REMark. 2014, 13, 56-73. DOI: https://doi.org/10.5585/remark.v13i2.2717. 